\title{
Amygdala activity in obsessive-compulsive disorder with contamination fear: a study with oxygen-15 water positron emission tomography
}

\author{
Odile A. van den Heuvel $^{\mathrm{a}, \mathrm{b}, *}$, Dick J. Veltman ${ }^{\mathrm{a}, \mathrm{b}}$, Henk J. Groenewegen ${ }^{\mathrm{c}}$, \\ Raymond J. Dolan ${ }^{\mathrm{d}}$, Danielle C. Cath ${ }^{\mathrm{a}}$, Ronald Boellaard ${ }^{\mathrm{b}}$, Catalina T. Mesina ${ }^{\mathrm{b}}$, \\ Anton J.L.M. van Balkom ${ }^{\mathrm{a}}$, Patricia van Oppen ${ }^{\mathrm{a}}$, Menno P. Witter ${ }^{\mathrm{c}}$, \\ Adriaan A. Lammertsma ${ }^{\mathrm{b}}$, Richard van Dyck ${ }^{\mathrm{a}}$ \\ ${ }^{a}$ Department of Psychiatry, VU University Medical Center and GGZ Buitenamstel, Valeriusplein 9, 1075 BG Amsterdam, The Netherlands \\ ${ }^{\mathrm{b}}$ PET Center, VU University Medical Center, P.O. Box 7057, 1007 MB Amsterdam, The Netherlands \\ ${ }^{\mathrm{c}}$ Department of Anatomy, VU University Medical Center, P.O. Box 7057, 1007 MB Amsterdam, The Netherlands \\ ${ }^{\mathrm{d}}$ Wellcome Department of Imaging Neuroscience, London WC1N 3BG, United Kingdom
}

Received 11 November 2003; received in revised form 26 May 2004; accepted 5 June 2004

\begin{abstract}
Previous imaging studies of obsessive-compulsive symptom states have implicated frontal-striatal and limbic regions in the pathophysiology of obsessive-compulsive disorder (OCD). Functional imaging studies, however, have yielded inconsistent results, presumably due to methodological differences (patient inclusion criteria, stimulus paradigm, imaging technique, and absence of control groups). In the present study, randomized presentation of contamination-related and neutral visual stimuli was used to investigate the neurophysiological correlates of contamination fear in a group of medication-free OCD patients with washing behaviors and healthy controls. A total of 21 subjects (11 OCD patients and 10 healthy controls) were scanned using $\mathrm{H}_{2}^{15} \mathrm{O}$ positron emission tomography (PET). Subjects were presented with pictures of clean and dirty surroundings and were requested to make indoor/outdoor decisions to control for attention differences. State anxiety and obsessionality were rated after each scan using visual analogue scales. Main effects of stimulus type (contamination vs. neutral) were found in bilateral occipital cortex in both groups. A significant group interaction effect was observed in the left amygdala reflecting enhanced activity in response to contamination stimuli in OCD patients. Sensitization effects were observed in the right amygdala in the OCD group; these paralleled an increase in levels of distress and obsessionality as well as a decrease in dorsolateral prefrontal activity. The findings of the present study are
\end{abstract}

* Corresponding author. PET Center, VU University Medical Center, P.O. Box 7057, 1007 MB Amsterdam, The Netherlands. Tel.: +31 20 4449635; fax: +31204449636 .

E-mail address: oa.vandenheuvel@vumc.nl (O.A. van den Heuvel). 
consistent with the hypothesis of decreased frontal-striatal control of limbic structures, specifically the amygdala, resulting in an inadequate fear response in OCD patients with contamination fear.

(C) 2004 Elsevier Ireland Ltd. All rights reserved.

Keywords: OCD; $\mathrm{H}_{2}^{15} \mathrm{O}$; PET; Contamination; Amygdala; Frontal-striatal

\section{Introduction}

Obsessive-compulsive disorder (OCD) is a common psychiatric disorder, affecting more than $1 \%$ of the population (Rasmussen and Eisen, 1992). This chronic disorder generally manifests itself first during adolescence and has a fluctuating course during adult life. OCD is characterized by recurrent intrusive thoughts (obsessions) and repetitive ritualistic behaviors (compulsions). These rituals can be highly time consuming and result in considerable morbidity, whereas concomitant anxiety symptoms often are less prominent at clinical presentation.

Although the pathogenesis of OCD is incompletely understood, a number of neuroimaging studies have reported neuroanatomical and functional abnormalities in OCD, particularly involving prefrontal-striatal and limbic regions. These studies, both volumetric and functional, have not yielded unequivocal results, however. Structural abnormalities in OCD have been described in the caudate nucleus in some studies (Luxenberg et al., 1988; Scarone et al., 1992; Rosenberg et al., 1997), whilst in other studies no differences between OCD patients and normal controls were evident (Kellner et al., 1991; Aylward et al., 1996). Jenike et al. (1996), using magnetic resonance imaging (MRI), found significantly diminished total white matter and increased total cerebral cortex and opercular volumes in OCD patients compared with controls. These results were only partially confirmed by Kim et al. (2001), who found increased gray matter (GM) density in frontal subcortical areas, but decreased GM density in other regions, in particular the cerebellum. In contrast, Szeszko et al. (1999) reported reduced orbitofrontal and amygdala volumes (both GM and white matter), and lack of normal hemispheric asymmetry of the hippocampusamygdala complex. Although these inconsistencies may reflect various methodological differences such as patient inclusion criteria, imaging modality, and data-analytic techniques, they also suggest that volumetric abnormalities in OCD, if present, are at best subtle.

Early functional imaging studies in OCD have been performed using positron emission tomography (PET), with ${ }^{18}$ fluoro-deoxyglucose (FDG) as a tracer, assessing resting state glucose metabolism (Baxter et al., 1987, 1988; Nordahl et al., 1989; Swedo et al., 1989). Baxter et al. (1987) reported hypermetabolism of the left orbital gyrus and bilateral caudate nucleus. In addition, striatal hypermetabolism normalized after successful treatment, either pharmacotherapy (Baxter et al., 1992) or behavioral therapy (Schwartz et al., 1996). The normalizing effect of pharmacotherapy on caudate hyperactivity has been replicated by many groups (Benkelfat et al., 1990; Swedo et al., 1992; Saxena et al., 2002; Hansen et al., 2002). In a similar vein, Rauch et al. (2002) found that increased regional cerebral blood flow (rCBF) in orbitofrontal and posterior cingulate cortices before treatment were predictive of response to pharmacotherapy in OCD patients with prominent contamination fear.

To our knowledge, at present, six imaging studies in OCD have been published in which symptom provocation was employed to differentiate between state and trait aspects. In a $\mathrm{H}_{2}^{15} \mathrm{O}$ PET study, McGuire et al. (1994) used tactile stimuli (various contaminants sealed in glass tubes) in four medication-free male OCD patients. Symptom scores (and state anxiety) were correlated with increased activity in the right inferior frontal gyrus, basal ganglia, thalamus, left hippocampus and posterior cingulate cortex. Rauch et al. (1994), using $\mathrm{C}^{15} \mathrm{O}_{2}$ PET, similarly compared responses to individually tailored provocative vs. neutral stimuli in a sample of eight male OCD patients and found increased relative regional cerebral blood flow during OCD symptom vs. resting state in bilateral orbitofrontal cortex, right 
caudate nucleus and left anterior cingulate cortex. The same group performed a similar study in 10 OCD patients 2 years later, using functional MRI (fMRI), also with idiosyncratic tactile stimuli (Breiter et al., 1996b). Contrasting provoked vs. neutral state, increased activity was found in the medial, right dorsolateral, and left ventrolateral prefrontal cortices (PFC), as well as in bilateral temporal cortex. At a lower statistical threshold, insular and anterior medial temporal regions were also found to be more active in the majority of patients. Since 9 out of 10 OCD subjects in the study of Breiter et al. (1996b) were taking medication at the time of scanning, Adler et al. (2000) replicated the study in medication-free OCD patients and reported increased activity in the orbitofrontal, anterior cingulate, bilateral anterior and lateral temporal cortices, as well as the right medial temporal cortex, during symptom provocation compared with baseline.

In two studies, OCD subcategories were investigated. Cottraux et al. (1996) used neutral vs. idiosyncratic obsession-related auditory scripts during $\mathrm{H}_{2}^{15} \mathrm{O}$ PET in 10 OCD patients with checking rituals and in 10 normal controls. In both groups, orbitofrontal perfusion was higher during provoked vs. neutral state. In addition, regional cerebral blood flow was higher in basal ganglia in controls. Finally, Phillips et al. (2000) compared 'checkers' and 'washers' using standardized visual stimuli during functional MR imaging. Similar to the results of Cottraux et al., increased frontal-striatal activity in 'checkers' and normal controls was found. In contrast, insular activity was observed in 'washers', although these effects did not survive in an interaction analysis. A methodological drawback of the Phillips et al. study was that the majority of patients were being treated with psychotropic medication.

Taken together, these studies have implicated a number of regions in the pathophysiology of OCD. It has been hypothesized that frontal-striatal involvement reflects ritualistic behavior, even in normal subjects (Cottraux et al., 1996), whereas increased medial temporal activity has been associated with (pathological) anxiety (McGuire et al., 1994), and insular activity with disgust (Phillips et al., 1997, 2000).

Similar to volumetric studies, inconsistent findings in functional imaging studies in OCD may result from a number of methodological issues, such as different imaging modalities, medication status, and small sample size. In addition, in all studies, with the exception of Phillips et al. (2000), individually tailored and therefore heterogeneous stimuli were used, i.e. not only contaminants, but also stimuli related to aggression/danger or sexual obsessions. Therefore, it cannot be ruled out that different symptoms are associated with different neuronal substrates. In addition, the use of idiosyncratic stimuli prohibits assessment of group by task interactions. Moreover, most studies used tactile stimuli, which may necessitate ritual behavior (hand washing), interrupting the scanning session. Consequently, in these studies off-on paradigms had to be used, carrying the risk of order effects. For example, in a recent PET study, it was shown that condition-related subject motion might produce considerable falsepositives due to transmission-emission mismatches (van den Heuvel et al., 2003).

In the present study, we aimed at investigating neurophysiological correlates of contamination fear. Only OCD subjects with prominent contamination fear were included, and presented with 'clean' vs. 'dirty' stimuli. Similar to the Phillips et al. (2000) study, visual stimuli, matched for visual complexity, were used, thereby obviating the need for cleaning rituals. Moreover, these stimuli, although ranging in severity, are universally aversive, so that the same paradigm could be used both in patients and control subjects. In contrast to the Phillips et al. study, we included only medication-free OCD patients. Finally, $\mathrm{H}_{2}^{15} \mathrm{O}$ PET rather than fMRI was used, as the advantage of high spatial resolution (fMRI) was offset by the advantages of PET, i.e. having scanning windows interspersed with rest to allow return to baseline, a smaller risk of claustrophobic reactions, and the absence of susceptibility artifacts in regions of interest such as the anterior medial temporal lobe, in particular in the amygdala, and orbitofrontal cortex. Each subject had eight scans ( 4 active and 4 baseline), randomized across subjects (11 medication-free OCD patients and 10 normal controls), which allowed examination of condition by time interactions. The specific experimental prediction was that contamination fear would result in recruitment of those circuitries hypothesized to play a role in ritualistic behavior (frontal-striatal system), anxiety (amygdala) and disgust (insula). 


\section{Methods}

\subsection{Subjects}

Eleven medication-free OCD patients ( 3 women, 8 men, age $40.5 \pm 9.2$ years) and 10 normal control subjects ( 3 women, 7 men, age $36.5 \pm 8.8$ years) were included. All subjects were right-handed. Exclusion criteria were the presence of major medical illness, other major psychiatric disorders, and the use of psychotropic medication. Diagnosis was established using the Structured Clinical Interview for DSM-IV Axis I Disorders (SCID-I). The Yale Brown Obsessive-Compulsive Scale (Y-BOCS) (Goodman et al., 1989) and the Padua Inventory-revised (Padua-IR) (Sanavio, 1988; van Oppen et al., 1995) were used to assess symptom characteristics and severity scores. Only subjects with prominent contamination fear as measured with the Y-BOCS symptom checklist were included. Scores on the Y-BOCS and Padua-IR for OCD patients were $23.8 \pm 6.1$ and $73.3 \pm 22.5$,

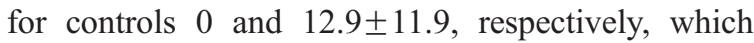
represented significant differences [Y-BOCS: $F(1,19)=179.4, \quad P<0.001$; Padua-IR: $F(1,19)=50.0$, $P<0.001]$. Subjects were recruited from the Outpatient Department of Psychiatry, VU University Medical
Center and the Dutch Phobia Organization. All subjects gave written informed consent. The protocol was approved by the Medical Ethical Committee of the VU University Medical Center.

\subsection{OCD symptom provocation paradigm}

Visual stimuli were presented to each subject to provoke contamination fear while PET data were obtained. A scanning session consisted of eight randomly ordered $\mathrm{H}_{2}^{15} \mathrm{O}$ PET scans: 4 in the control condition (clean pictures) and 4 in the symptom condition (dirty pictures). Twenty seconds after injection of $\mathrm{H}_{2}^{15} \mathrm{O}, 11$ pictures were presented sequentially on a high-resolution flat screen. Each picture was shown for $3 \mathrm{~s}$, followed by a 1-s blank screen. To control for attention, subjects were asked to indicate for each picture (using a response box) whether it represented an indoor or outdoor situation. After each scan, a resting period of 8 min followed. During this resting phase, subjects were asked to rate subjective distress (ANX) and obsessionality (OBS) using 100-point analogue scales. In total, 44 different dirty and 44 clean pictures were presented to each subject (examples are shown in Fig. 1).
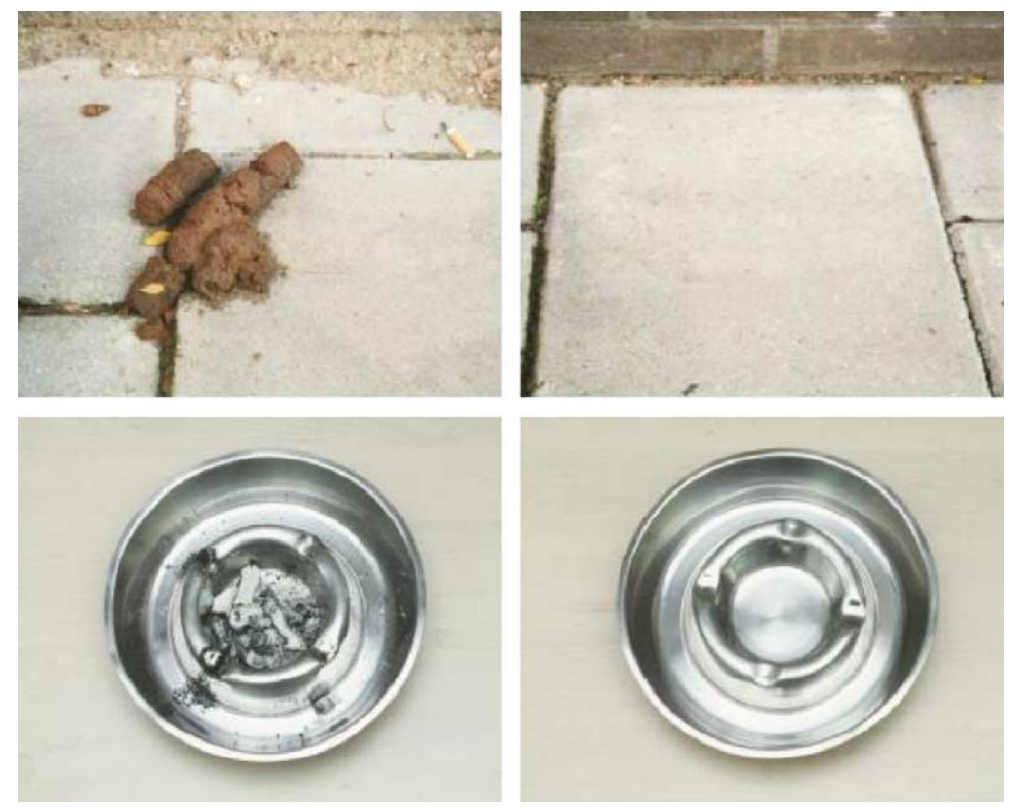

Fig. 1. Examples of dirty and clean pictures in the symptom-provocation design. 


\subsection{Image acquisition and reconstruction}

PET scans were acquired on an ECAT EXACT HR+ scanner (CTI/Siemens, Knoxville, TN), the characteristics of which are well documented (Adam et al., 1997). Prior to each scanning session, a cannula was inserted into the left antecubital vein and normal saline was infused. A transmission scan was performed first for the purpose of attenuation correction of the subsequent emission scans. For each emission scan, 10-15 $\mathrm{ml}$ normal saline containing $450 \mathrm{MBq}$ of $\mathrm{H}_{2}^{15} \mathrm{O}$ was administered as a bolus injection using an infusion pump. Data acquisition lasted $90 \mathrm{~s}$ (20 s before, $44 \mathrm{~s}$ during and $26 \mathrm{~s}$ after stimulus presentation) and the interval between successive $\mathrm{H}_{2}^{15} \mathrm{O}$ injections was 8 min to allow for radioactive decay. In the present study, transmission scans of $10 \mathrm{~min}$ were acquired in $2 \mathrm{D}$ mode for all studies. All emission scans were acquired in $3 \mathrm{D}$ mode. To rule out task-related motion artifacts, data were reconstructed using an image registration method (van den Heuvel et al., 2003) with ordered subset expectation maximization (OSEM) (Shepp and Vardi, 1982; Hudson and Larkin, 2003) applying four iterations with 16 subsets (Mesina et al., 2003). For each subject, a T1-weighted structural MR scan was also acquired using a 1.5-T Sonata (Siemens, Erlangen) MR scanner [magnetization prepared-rapid acquisition gradient echo (MP-RAGE); inversion time $=300 \mathrm{~ms}$, $\mathrm{TR}=15 \mathrm{~ms}$, $\mathrm{TE}=7 \mathrm{~ms}$, flip angle $=8^{\circ}$, voxel size $=$ $1 \times 1 \times 1.5 \mathrm{~mm}]$.

\subsection{Statistical analysis}

Behavioral data were analyzed using a standard statistical package. After reconstruction, PET images were analyzed using SPM99 (Wellcome Department of Cognitive Neurology, http://www.fil.ion.ucl.ac.uk/ $\mathrm{spm})$. Spatial preprocessing consisted of realignment, transformation to approximate Talairach (Talairach and Tournoux, 1988) anatomical standard space, as defined by the SPM99 template, and smoothing using a 10-mm Gaussian filter instead of the customary 16 $\mathrm{mm}$ for PET group studies, resulting in an overall FWHM of $12 \mathrm{~mm}$. Since the human amygdala is about $15 \mathrm{~mm}$, the present smoothing is considered to be optimal to detect activation changes, which are just over $12 \mathrm{~mm}$ in diameter (Poline and Mazoyer, 1994). Data were analyzed using a linear regression model. Weighted contrasts were computed for condition and time effects for each group, and for group by condition interactions. Analyses of covariance were also performed to assess correlations between imaging data and psychometric measurements. In view of the smoothness of the data after spatial preprocessing (ca. 12-mm FWHM), a combined height and extent threshold was used to report main effects of $P<0.001$ uncorrected with an extent threshold of 25 voxels. Interactions (group by task, and group by time) were masked with the appropriate main effect and are reported at $P<0.001$ uncorrected, with an extent threshold of five voxels.

\section{Results}

\subsection{Psychometric data}

Among patients, OBS scores reflected increased OCD symptomatology during the active condition vs. baseline (paired $t$-test: $30.3 \pm 22.4$ vs. $9.3 \pm 13.0$, $P=0.003$, one-tailed). An increase in OBS scores was also observed in normal controls $(15.9 \pm 17.9$ vs. $0.6 \pm 1.0, P=0.02$, two-tailed). As expected, in the OCD group, subjective distress as expressed by ANX scores was higher during the active condition than during baseline $(32.1 \pm 18.3$ vs. $26.1 \pm 21.4, P=0.05$, one-tailed). For control subjects, we found no significant active vs. baseline increase in ANX scores (7.2 \pm 5.4 vs. $9.3 \pm 6.9, P>0.1$, two-tailed). Comparisons between the two groups revealed that OBS scores were higher in the OCD group at rest [ANOVA: $F(1,19)=4.4, P=0.05]$ but not during the active condition $[F(1,19)=2.6, P>0.1]$. ANX scores were higher in the OCD group at baseline $[F(1,19)=$ 7.4, $P=0.01]$ as well as during the active condition $[F(1,19)=13.7, P=0.002]$. Condition by time interactions were found only in the OCD group during the active condition, ANX and OBS scores showing an increase from the first (early) to the second (late) part of the session (ANX scores: 20.5 $\pm 33.9, P=0.09$; OBS scores: $24.0 \pm 28.6, P=0.03$ ). Correlations between mean ANX and OBS ratings were only statistically significant during the active condition in the OCD group ( $r=0.63, P=0.04)$. 
Table 1

Main effects in 11 OCD patients, contamination versus neutral stimuli

\begin{tabular}{lllll}
\hline \multicolumn{2}{l}{ Contamination $>$ baseline } \\
\hline Region & Coordinates & Cluster size & BA & $Z$-score \\
\hline Left amygdala region & $-18,-4,-16$ & 202 & - & $4.8^{* *}$ \\
Left occipital cortex & $-44,-78,6$ & 168 & 19 & $4.0^{*}$ \\
Right occipital cortex & $30,-68,-14$ & 99 & 19 & $4.2^{*}$ \\
\hline
\end{tabular}

Brodmann's area (BA).

* $P<0.001$ uncorrected for multiple comparisons.

** $P<0.05$ corrected for multiple comparisons.

\subsection{PET data}

Main effects of symptom compared with baseline condition are listed in Tables 1 and 2. Provocation of contamination fear in OCD patients was correlated with increased regional cerebral blood flow (rCBF) in the left amygdala, extending into left anterior temporal cortex, left entorhinal cortex and hypothalamus, with additional activity in bilateral extrastriatal cortex (Fig. 2a). In control subjects, increased rCBF was found in left dorsolateral prefrontal cortex, basal forebrain extending into orbitofrontal cortex, right caudate nucleus, left anterior temporal cortex and bilateral extrastriatal cortex (Fig. 2b). Group by condition interactions were found in the left amygdala region, reflecting relative enhanced activity to contamination stimuli in the OCD group with relative decreases in left dorsolateral prefrontal cortex and right caudate nucleus (i.e., enhanced activity in normal controls) (Table 3 and Fig. 2c). Finally, significant time by condition interactions were observed in the right amygdala region in the OCD group, but not in controls (group by time by condition ANOVA, $z$-score $=2.75, P=0.003$ uncorrected, see Fig. $3 a)$, corresponding to a decrease in $\mathrm{rCBF}$ in this region during the successive resting state conditions and an increase in $\mathrm{rCBF}$ during the successive active conditions (Fig. 3b). These differential time courses for left and right amygdala in the provocation condition were confirmed by a region of interest (ROI) analysis, demonstrating a statistically significant negative correlation between left and right amygdala signal $(r=-0.35, P=0.022)$.

Results of correlational analyses are listed in Table 4. In the OCD group, OBS scores were correlated with increased activation of bilateral occipital cortex and decreased activation of right ventromedial prefrontal cortex, dorsolateral prefrontal cortex, and right parietal cortex. No statistically significant correlations were found between ANX scores and $\mathrm{rCBF}$ changes.

\section{Discussion}

In the present study, $\mathrm{H}_{2}^{15} \mathrm{O}$ PET was used to investigate the neurophysiological correlates of contamination fear in a subgroup of obsessive-compulsive washers and healthy control subjects. To this end, rCBF was compared in both groups during presentation of neutral and contamination-related visual stimuli. Behavioral data showed that the present design was successful in inducing both increased subjective distress (ANX) and obsessionality (OBS). In the OCD group, ANX and OBS ratings were only moderately high, but showed an increase over time,

Table 2

Main effects in 10 control subjects, contamination versus neutral stimuli

\begin{tabular}{|c|c|c|c|c|}
\hline \multicolumn{5}{|l|}{ Contamination $>$ baseline } \\
\hline Region & Coordinates & Cluster size & BA & $Z$-score \\
\hline Left dorsolateral prefrontal cortex & $-18,44,32$ & 96 & 9 & $3.7^{*}$ \\
\hline \multirow[t]{2}{*}{ Basal forebrain/posterior orbitofrontal cortex } & $0,0,-4$ & 261 & 25 & $4.1^{*}$ \\
\hline & $4,12,-14$ & & & $3.9^{*}$ \\
\hline Right caudate nucleus & $18,10,14$ & 37 & - & $3.7^{*}$ \\
\hline Left anterior temporal cortex & $-42,28,-24$ & 82 & 38 & $3.9 *$ \\
\hline Left occipital cortex & $-44,-84,0$ & 42 & 19 & $3.7^{*}$ \\
\hline Right occipital cortex & $26,-80,-18$ & 63 & 19 & $3.9^{*}$ \\
\hline
\end{tabular}

Brodmann's area (BA).

* $P<0.001$ uncorrected for multiple comparisons. 

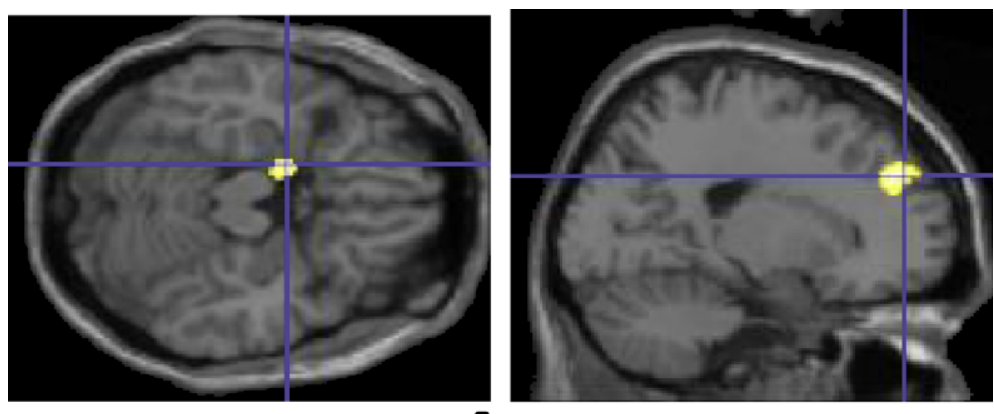

a
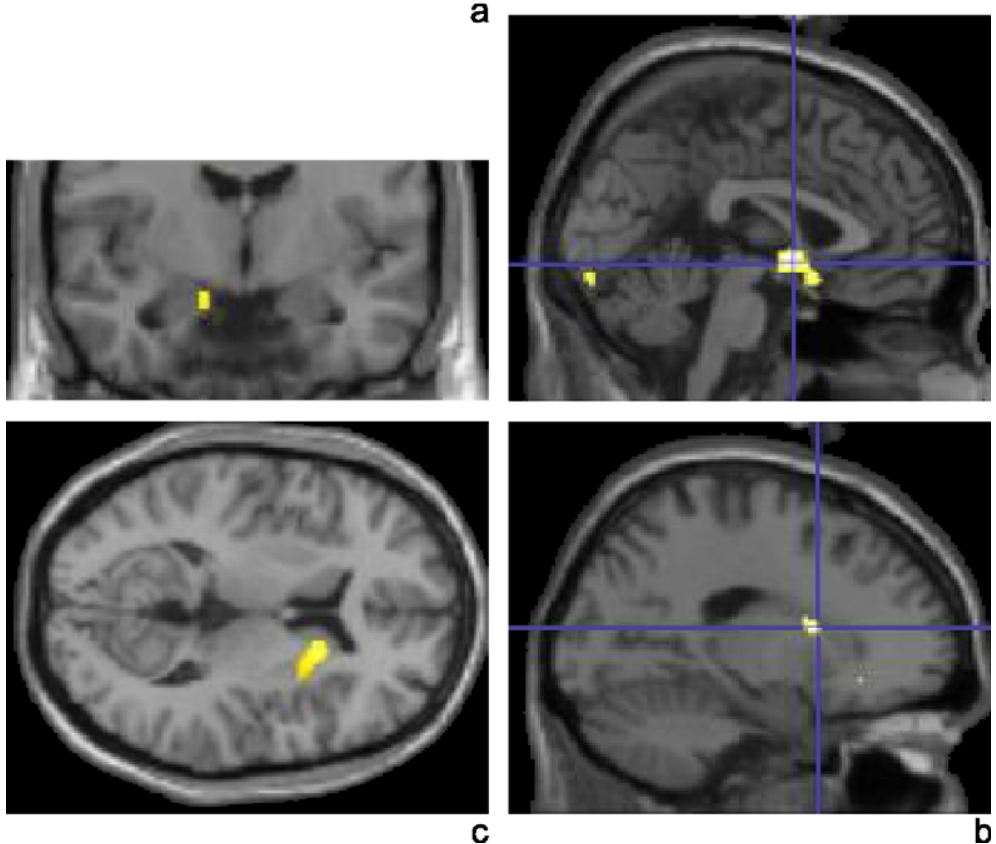

Fig. 2. (a) Positron emission tomography subtraction images of provoked minus resting conditions for 11 OCD patients displayed on mean T1weighted magnetic resonance image show activation in left amygdala (Talairach coordinates $x, y, z=-18,-4,-16$ ). (b) Positron emission tomography subtraction images of provoked minus resting conditions for 10 control subjects displayed on mean T1-weighted magnetic resonance image show activation in left dorsolateral prefrontal cortex (Talairach coordinates $x, y, z=-18,44,32$ ), basal forebrain (Talairach coordinates $x, y, z=4,12,-14$ ) and right caudate nucleus (Talairach coordinates $x, y, z=18,8,16$ ). (c) Group by condition interaction analysis, showing increased rCBF in left amygdala (Talairach coordinates $x, y, z=-18,-4,-16$ ) during provoked versus resting conditions in OCD patients compared with control subjects and in right caudate nucleus (Talairach coordinates $x, y, z=18,8,16$ ) in control subjects compared with OCD patients (statistical significance was thresholded at uncorrected $P=0.01$ for display purposes).

implying that OCD patients became more sensitive, rather than habituated, to contamination stimuli. Nevertheless, all subjects were able to complete the scanning session.

Imaging data showed that symptom provocation in OCD patients was correlated with increased $\mathrm{rCBF}$ in left amygdala and bilateral extrastriatal cortex, while control subjects showed increased activation of the basal forebrain extending into posterior orbitofrontal cortex, left dorsolateral prefrontal cortex, right caudate nucleus and bilateral extrastriatal cortex. Group by condition interactions were found in the left amygdala in the OCD group and in the left dorsolateral prefrontal cortex and right caudate in controls, whereas significant time by condition interactions were only observed in the right amygdala in the OCD group. The finding of amygdala involvement in OCD subjects during symptom vs. neutral condition is in 


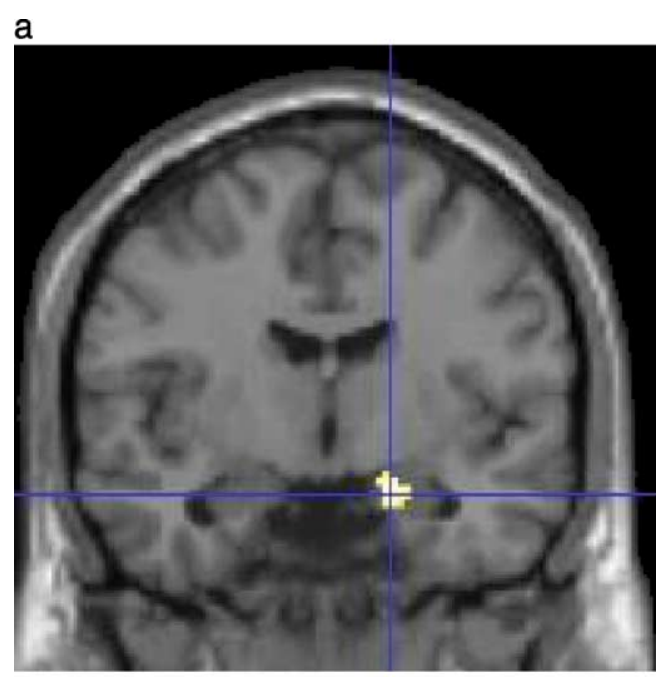

\section{b Contrast of parameter estimates effects of interest}

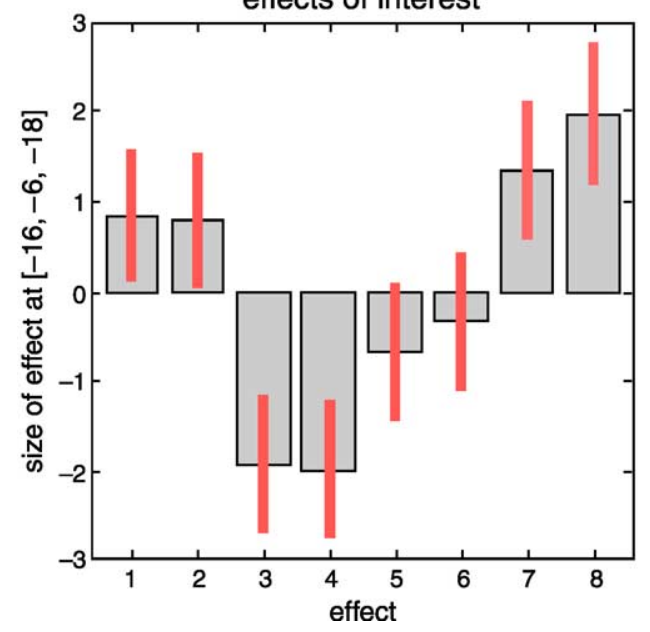

Fig. 3. (a) Positron emission tomography time by condition contrast images for 11 OCD patients displayed on mean T1-weighted magnetic resonance image show activation in right amygdala (Talairach coordinates $x, y, z=16,-6,-18$ ). (b) Plot of effect size ( $y$-axis) in right amygdala for time by condition analysis in $11 \mathrm{OCD}$ patients. Plot shows decreasing effect size over time during subsequent resting conditions ( $x$-axis: $1,2,3,4)$ and increasing effect size over time during subsequent provoked conditions $(x$-axis: $5,6,7,8)$.

agreement with a number of studies using fear paradigms in normal controls (Morris et al., 1996, 1998a,b; Phillips et al., 1997, 2001; Wright et al., 2001; Whalen et al., 2001; Fischer et al., 2003), supporting the role of the amygdala as a key structure in evaluating the behavioral significance of external stimuli (LeDoux, 1996). Previous imaging studies in OCD, however, have observed amygdala involvement only in small subgroups and/or at lower statistical thresholds (Breiter et al., 1996b; Adler et al., 2000), or not at all (McGuire et al., 1994; Rauch et al., 1994; Cottraux et al., 1996; Phillips et al., 2000). Possible explanations include statistical power (repeated measures vs. off-on paradigms) and stimulus type. Although the amygdala receives multimodal sensory information, projections from visual processing areas are particularly prominent (Amaral et al., 2003). Therefore, salient visual stimuli may give rise to amygdala activation more easily than tactile or auditory stimuli. In addition, the use of antidepressants is likely to suppress amygdala function (see Drevets, 2003, for a review).

In both groups, greater activity of bilateral extrastriatal cortex in the active condition than in the baseline condition was observed. It has been postulated that these secondary visual areas play a critical role in perceptual processing of socially and emotionally relevant stimuli (Breiter et al., 1996a; Morris et al., 1998a; Adolphs, 2002). Morris et al. (1998a) demonstrated that activation of the amygdala resulted in context-dependent modulatory effects in extrastriatal cortex. Lane et al. (1999) investigated the interaction between emotion and attention in visual processing and found the extrastriatal visual cortex as well as the anterior temporal cortex activated by emotional valence, arousal and attention. In the present study, increased activity in the left anterior temporal pole during the active condition was found in the control group. The role of the anterior temporal cortex, as a hierarchically higher order cortical area involved in visual processing and evaluation of the significance of current stimuli, might include retrieval of past emotional experiences. The anterior temporal cortex has reciprocal connections to frontal areas, in particular, orbitomedial prefrontal areas, thus enabling associated behavioral responses.

In the present study, differential effects in left and right amygdala were found. OCD patients showed increased activity in the left amygdala during the symptom condition, an effect that was stable over time. This left-lateralized response is in accordance with results of earlier studies in normal volunteers (Morris et al., 1996; Phillips et al., 1997, 2001; Morris et al., 1998a,b; Wright et al., 2001). However, in favor 
Table 3

Condition (contamination versus neutral stimuli) by group interactions

\begin{tabular}{|c|c|c|c|c|}
\hline Region & Coordinates & Cluster size & BA & $Z$-score \\
\hline \multicolumn{5}{|l|}{ OCD $>$ controls } \\
\hline Left amygdalar region & $-18,-6,-18$ & 7 & - & $3.4^{*}$ \\
\hline \multicolumn{5}{|l|}{ Controls $>O C D$} \\
\hline Left dorsolateral prefrontal cortex & $-18,44,32$ & 96 & 9 & $3.4^{*}$ \\
\hline Right caudate nucleus & $18,10,14$ & 37 & - & $3.3^{*}$ \\
\hline
\end{tabular}

Brodmann's area (BA).

* $P<0.001$ uncorrected for multiple comparisons.

of the OCD group versus healthy control subjects, a significant time by condition interaction was observed in the right amygdala, i.e. a signal decrease over time in the baseline condition compared with an increase during the symptom condition. This effect has not been described in previous OCD studies, but is likely to reflect the increase in ratings of subjective distress and obsessionality over time observed in the OCD group. In normal volunteers, a number of investigators have reported habituation, not sensitization, of amygdala responses to alarming stimuli (Breiter et al., 1996a; Morris et al., 1996; Fischer et al., 2000; Wright et al., 2001; Phillips et al., 2001). These effects have mostly been found in the right amygdala, but not in the left, from which it has been concluded that the right amygdala is involved in rapid emotional stimulus detection, whereas the left amygdala is associated with sustained stimulus evaluation. Alternatively, Morris et al. (1998b) proposed that the left amygdala has a role in conscious stimulus processing, whilst the right amygdala is associated with unconscious processing. Neither hypothesis, however, fits the data from the present study. A possible explan- ation is provided by the work of Schaefer et al. (2002), who found increased amygdala activity when subjects maintained the negative emotional response during the delay following visual presentation of negative stimuli. This increase in amygdala response correlated with self-reported levels of negative affect. These findings suggest that maintenance of emotional responses by cognitive processes may operate, at least in part, by modulating neural activity within the amygdala. Similarly, Siegle et al. (2002) reported that in subjects with major depression, processing of negative stimuli was associated with prolonged bilateral amygdala activity. Moreover, these responses were related to self-reported rumination. In the present study, however, due to the limited temporal resolution of $\mathrm{H}_{2}^{15} \mathrm{O}$ PET, it was impossible to determine whether the sensitization effects observed in the OCD subjects were due to increases in amplitude or duration of responses to individual stimuli.

Contrary to expectations, when contrasting symptom vs. baseline conditions, orbitofrontal activity was only observed in the control group, but failed to reach significance in the OCD group. Moreover,

Table 4

Covariation with OBS scores in 11 OCD patients

\begin{tabular}{|c|c|c|c|c|}
\hline Region & Coordinates & Cluster size & BA & $Z$-score \\
\hline \multicolumn{5}{|l|}{ Increase } \\
\hline \multirow[t]{2}{*}{ Right occipital cortex } & $40,-90,2$ & 58 & 18 & $4.2^{*}$ \\
\hline & $40,-74,8$ & 127 & 19 & $3.9^{*}$ \\
\hline Left occipital cortex & $-44,-78,8$ & 148 & 19 & $4.2^{*}$ \\
\hline \multicolumn{5}{|l|}{ Decrease } \\
\hline Right ventromedial prefrontal cortex & $34,52,-14$ & 87 & 11 & $3.7^{*}$ \\
\hline Right dorsolateral prefrontal cortex & $46,34,32$ & 30 & 9 & $3.7^{*}$ \\
\hline Right parietal cortex & $44,-54,44$ & 179 & 40 & $4.1^{*}$ \\
\hline
\end{tabular}

Brodmann's area (BA).

* $P<0.001$ uncorrected for multiple comparisons. 
group by condition interaction effects in basal ganglia and dorsolateral prefrontal cortex were found in favor of normal controls compared with OCD patients. Involvement of the basal ganglia during symptom provocation in OCD subjects has been reported in most (McGuire et al., 1994; Rauch et al., 1994; Breiter et al., 1996b), but not all (Adler et al., 2000), previous studies, a finding that was attributed by Adler et al. (2000) to differences in medication status. Although in the present study only medication-free patients were included, this does not seem to be a plausible explanation since subjects in some of the above-mentioned studies were off medication as well (McGuire et al., 1994; Rauch et al., 1994). Whether paradigms employing tactile stimuli are generally more likely to produce basal ganglia activity is difficult to ascertain since most earlier studies lacked control groups. A possible explanation for the apparent lack of frontal-striatal involvement in OCD patients is increased baseline regional perfusion, as suggested by the resting state FDGPET studies by Baxter et al., (1987, 1988). To investigate this issue, we performed a post hoc analysis comparing relative baseline activity between the two groups. OCD patients compared with controls, showed increased activity in orbitofrontal and insular cortices; however, no differences were found in the basal ganglia (data not shown). These findings seem to be in agreement with those of Cottraux et al. (1996), who found increased orbitofrontal perfusion during provoked vs. neutral state in both OCD patients and healthy control subjects, presumably reflecting ritualistic behavior. In addition, increased activity in the basal ganglia was found in controls, but not in OCD patients. Increased frontal-striatal involvement in controls in response to contamination-related stimuli was also found by Phillips et al. (2000). While controls and 'checkers' recruited the frontal-striatal system, contaminationfearing OCD patients showed increased activity in the insular cortex, important in disgust perception.

Taken together, imaging findings from the present study indicate that presentation of contaminationrelated stimuli in normal subjects results in activation of regions assumed to be involved in higher order control. In contrast, in OCD subjects, condition effects were primarily observed in areas associated with processing of salient (i.e., threatening) stimuli. This interpretation receives some support from our finding that OBS ratings increased in both groups, but ANX ratings increased only in the OCD group. Moreover, ANX and OBS ratings showed significant correlations only during the symptom condition in the OCD group. However, we recognize that the specificity of the visual analogue scales used in the present study as well as in others is debatable (Rauch et al., 1994); in particular, OBS ratings may reflect not only urge to ritualize, but also disgust.

With regard to these two emotional states, Phillips et al. (1997) showed that separate regions were associated with fear and disgust. Whereas perception of fearful faces was correlated with activation of the left amygdala, perception of facial expressions of disgust was correlated with activation in right medial frontal and insular cortices. Very strong disgust also activated right putamen and thalamus, structures associated with the corticostriatal-thalamic circuit (Alexander, 1986). Sprengelmeyer et al. (1998) implicated right putamen and left insular cortex during presentation of disgusted, but not fearful, facial expressions, in support of the hypothesis of distinct neural networks involved in basic emotions like fear and disgust. However, the issue of whether the neural representation of emotion involves separate systems for individual emotions, or an integrated system able to code all emotions, is still unresolved (Calder et al., 2001). Although several studies support the category-based model, indicating that the neural mechanisms underlying fear and disgust might be at least partly separate (Phillips et al., 1997; Sprengelmeyer et al., 1998), some studies also show amygdala involvement in perception of disgust, supporting a dimensional model (Schienle et al., 2002). Impaired recognition of disgust from facial expressions has been reported in patients with OCD (Sprengelmeyer et al., 1997), Huntington's disease (Sprengelmeyer et al., 1996) and brain injury in the area of the basal ganglia and insular cortex (Calder et al., 2000). In contrast to the results of Phillips et al. (1997, 2000) and Sprengelmeyer et al. (1998), in the present study no task-related insular activity was found in the OCD group, although our post hoc results indicate that this may have been due to increased activity in insular cortex at baseline in OCD patients compared with controls. 
Finally, an explanation for the differential frontalstriatal involvement in the two groups in the present study is suggested by our finding that OBS ratings in OCD patients were inversely coupled to both ventromedial and dorsolateral prefrontal activity. An inverse correlation between OCD scores and prefrontal activity (albeit in the orbitofrontal cortex) was also reported by Rauch et al. (1994) and Adler et al. (2000). This finding was attributed to a loss of inhibitory input from frontal structures. Similarly, negative correlations between amygdala and dorsolateral prefrontal activity were demonstrated in depressed subjects in the study of Siegle et al. (2002). Therefore, we suggest that the observed differences between OCD patients and controls reflect a failure of frontal-striatal circuitry in OCD patients to control the processing of negative (contaminationrelated) stimuli, resulting in an inadequate fear response, involving bilateral amygdala. The present data also indicate that repeated stimulation may lead to sensitization in OCD subjects. However, because we studied only OCD subjects with prominent contamination fear, these findings cannot be generalized to other OCD subtypes. Different OCD symptom dimensions might be associated with differential patterns of activation in ventral prefrontal, limbic and dorsal prefrontal regions (Mataix-Cols et al., 2003). Future research will need to investigate temporal characteristics of amygdala responses in OCD patients, to compare contamination and general threat stimuli in medication-free OCD patients and normal controls, and to compare OCD subgroups, by including subjects with prominent checking rituals. To investigate the specificity of the neurophysiological abnormalities found in OCD, comparison with results in other anxiety disorders, like hypochondriasis and panic disorder, or with mood disorders is important. Pretreatment-posttreatment studies, in case of pharmacotherapy as well as psychotherapy, may result in a more detailed understanding of influences on the frontal-striatal system.

\section{Acknowledgments}

We thank G. Luurtsema, J.M.P.A. Eyndhoven, H.N.J.M. Greuter, and P.L.B. Ophemert for their attribution to $\mathrm{H}_{2}^{15} \mathrm{O}$ production, and B.G. Hoving,
S.C.M. van Balen, R.H.A. Koopmans and A.M. de Wildt for their assistance during scanning sessions. This work was supported by the Dutch Organization for Scientific Research (NWO), MW 940-37-018.

\section{References}

Adam, L.E., Zaers, J., Ostertag, H., Trojan, H., Bellemann, M.E., Brix, G., 1997. Performance evaluation of the whole-body PET scanner ECAT EXACT HR+ following the IEC standard. IEEE Transactions on Nuclear Science 44, 1172-1179.

Adler, C.M., McDonough-Ryan, P., Sax, K.W., Holland, S.K., Arndt, S., Strakowski, S.M., 2000. fMRI of neuronal activation with symptom provocation in unmedicated patients with obsessive compulsive disorder. Journal of Psychiatric Research 34, 317-324.

Adolphs, R., 2002. Neural systems for recognizing emotion. Current Opinion in Neurobiology 12, 169-177.

Alexander, G.E., 1986. Parallel organization of functionally segregated circuits linking basal ganglia and cortex. Annual Review of Neuroscience 9, 357-381.

Amaral, D.G., Behiea, H., Kelly, J.L., 2003. Topographic organization of projections from the amygdala to the visual cortex in the macaque monkey. Neuroscience 118, 1099-1120.

Aylward, E.H., Harris, G.J., Hoehn-Saric, R., Barta, P.E., Machlin, S.R., Pearlson, G.D., 1996. Normal caudate nucleus in obsessive-compulsive disorder assessed by quantitative neuroimaging. Archives of General Psychiatry 53, 577-584.

Baxter Jr., L.R., Phelps, M.E., Mazziotta, J.C., Guze, B.H., Schwartz, J.M., Selin, C.E., 1987. Local cerebral glucose metabolic rates in obsessive-compulsive disorder. A comparison with rates in unipolar depression and in normal controls (published erratum appears in Archives of General Psychiatry, 1987, 44, 800, see comments). Archives of General Psychiatry 44, 211-218.

Baxter Jr., L.R., Schwartz, J.M., Mazziotta, J.C., Phelps, M.E., Pahl, J.J., Guze, B.H., Fairbanks, L., 1988. Cerebral glucose metabolic rates in nondepressed patients with obsessivecompulsive disorder. American Journal of Psychiatry 145, $1560-1563$.

Baxter Jr., L.R., Schwartz, J.M., Bergman, K.S., Szuba, M.P., Guze, B.H., Mazziotta, J.C., Alazraki, A., Selin, C.E., Ferng, H.K., Munford, P., 1992. Caudate glucose metabolic rate changes with both drug and behavior therapy for obsessive-compulsive disorder. Archives of General Psychiatry 49, 681-689.

Benkelfat, C., Nordahl, T.E., Semple, W.E., King, A.C., Murphy, D.L., Cohen, R.M., 1990. Local cerebral glucose metabolic rates in obsessive-compulsive disorder. Patients treated with clomipramine. Archives of General Psychiatry 47, 840-848.

Breiter, H.C., Etcoff, N.L., Whalen, P.J., Kennedy, W.A., Rauch, S.L., Buckner, R.L., Strauss, M.M., Hyman, S.E., Rosen, B.R., 1996a. Response and habituation of the human amygdala during visual processing of facial expression. Neuron 17, 875-887.

Breiter, H.C., Rauch, S.L., Kwong, K.K., Baker, J.R., Weisskoff, R.M., Kennedy, D.N., Kendrick, A.D., Davis, T.L., Jiang, A., 
Cohen, M.S., Stern, C.E., Belliveau, J.W., Baer, L., O'Sullivan, R.L., Savage, C.R., Jenike, M.A., Rosen, B.R., 1996b. Functional magnetic resonance imaging of symptom provocation in obsessive-compulsive disorder. Archives of General Psychiatry 53, 595-606.

Calder, A.J., Keane, J., Manes, F., Antoun, N., Young, A.W., 2000. Impaired recognition and experience of disgust following brain injury. Nature Neuroscience 3, 1077-1078.

Calder, A.J., Lawrence, A.D., Young, A.W., 2001. Neuropsychology of fear and loathing. Nature Reviews 2, 352-363.

Cottraux, J., Gerard, D., Cinotti, L., Froment, J.C., Deiber, M.P., Le Bars, D., Galy, G., Millet, P., Labbe, C., Lavenne, F., Bouvard, M., Mauguiere, F., 1996. A controlled positron emission tomography study of obsessive and neutral auditory stimulation in obsessive-compulsive disorder with checking rituals. Psychiatry Research 60, 101-112.

Drevets, W.C., 2003. Neuroimaging abnormalities in the amygdala in mood disorders. Annals of the New York Academy of Sciences 985, 420-444.

Fischer, H., Furmark, T., Wik, G., Fredrikson, M., 2000. Brain representations of habituation to repeated complex visual stimulation studied with PET. NeuroReport 11, 123-126.

Fischer, H., Wright, C.I., Whalen, P.J., McInerney, S.C., Shin, L.M., Rauch, S.L., 2003. Brain habituation during repeated exposure to fearful and neutral faces: a functional MRI study. Brain Research Bulletin 59, 387-392.

Goodman, W.K., Price, L.H., Rasmussen, S.A., Mazure, C., Fleischmann, R.L., Hill, C.L., Heninger, G.R., Charney, D.S., 1989. The Yale-Brown Obsessive Compulsive Scale, development, use and reliability. Archives of General Psychiatry 46, 1006-1011.

Hansen, E.S., Hasselbalch, S., Law, I., Bolwig, T.G., 2002. The caudate nucleus in obsessive-compulsive disorder. Reduced metabolism following treatment with paroxetine: a PET study. International Journal of Neuropsychopharmacology 5, 1-10.

Hudson, H.M., Larkin, R.S., 2003. Accelerated image reconstruction using ordered subsets of projection data. IEEE Transactions on Medical Imaging 13, 601-609.

Jenike, M.A., Breiter, H.C., Baer, L., Kennedy, D.N., Savage, C.R., Olivares, M.J., O’Sullivan, R.L., Shera, D.M., Rauch, S.L., Keuthen, N., Rosen, B.R., Caviness, V.S., Filipek, P.A., 1996. Cerebral structural abnormalities in obsessive-compulsive disorder. A quantitative morphometric magnetic resonance imaging study (see comments). Archives of General Psychiatry $53,625-632$.

Kellner, C.H., Jolley, R.R., Holgate, R.C., Austin, L., Lydiard, R.B., Laraia, M., Ballenger, J.C., 1991. Brain MRI in obsessivecompulsive disorder. Psychiatry Research 36, 45-49.

Kim, J.J., Lee, M.C., Kim, J., Kim, I.Y., Kim, S.I., Han, M.H., Chang, K.H., Kwon, J.S., 2001. Grey matter abnormalities in obsessive-compulsive disorder: statistical parametric mapping of segmented magnetic resonance images. British Journal of Psychiatry 179, 330-334.

Lane, R.D., Chua, P.M.L., Dolan, R.J., 1999. Common effects of emotional valence, arousal and attention on neural activation during visual processing of pictures. Neuropsychologia 37, 989-997.
LeDoux, J., 1996. The Emotional Brain: The Mysterious Underpinnings of Emotional Life. Touchstone, New York.

Luxenberg, J.S., Swedo, S.E., Flament, M.F., Friedland, R.P., Rapoport, J., Rapoport, S.I., 1988. Neuroanatomical abnormalities in obsessive-compulsive disorder detected with quantitative X-ray computed tomography. American Journal of Psychiatry 145, 1089-1093.

Mataix-Cols, D., Cullen, S., Lange, K., Zelaya, F., Andrew, C., Amaro, E., Brammer, M.J., Williams, S.C.R., Speckers, A., Phillips, M.L., 2003. Neural correlates of anxiety associated with obsessive-compulsive symptom dimensions in normal volunteers. Biological Psychiatry 53, 482-493.

McGuire, P.K., Bench, C.J., Frith, C.D., Marks, I.M., Frackowiak, R.S., Dolan, R.J., 1994. Functional anatomy of obsessivecompulsive phenomena. British Journal of Psychiatry 164, $459-468$.

Mesina, C.T., Boellaard, R., Jongbloed, G., van der Vaart, A.W., Lammertsma, A.A., 2003. Experimental evaluation of interactive reconstruction versus filtered back projection for $3 \mathrm{D}\left[{ }^{15} \mathrm{O}\right]$ water PET activation studies using statistical parametric mapping analysis. NeuroImage 19, 1170-1179.

Morris, J.S., Frith, C.D., Perrett, D.I., Rowland, D., Young, A.W., Calder, A.J., Dolan, R.J., 1996. A differential neural response in the human amygdala to fearful and happy facial expressions. Nature 383, 812-815.

Morris, J.S., Friston, K.J., Buchel, C., Frith, C.D., Young, A.W., Calder, A.J., Dolan, R.J., 1998a. A neuromodulatory role for the human amygdala in processing emotional facial expressions. Brain 121, 47-57.

Morris, J.S., Ohman, A., Dolan, R.J., 1998b. Conscious and unconscious emotional learning in the human amygdala. Nature 393, 467-470.

Nordahl, T.E., Benkelfat, C., Semple, W.E., Gross, M., King, A.C., Cohen, R.M., 1989. Cerebral glucose metabolic rates in nondepressed patients with obsessive-compulsive disorder. Neuropsychopharmacology 2, 23-28.

Phillips, M.L., Young, A.W., Senior, C., Brammer, M.J., Andrew, C., Calder, A.J., Bullmore, E.T., Perrett, D.I., Rowland, D., Williams, S.C.R., Gray, G.A., David, A.S., 1997. A specific neural substrate for perceiving facial expressions of disgust. Nature 389, 495-498.

Phillips, M.L., Marks, I.M., Senior, C., Lythgoe, D., O’Dwyer, A.M., Meehan, O., Williams, S.C.R., Brammer, M.J., Bullmore, E.T., McGuire, P.K., 2000. A differential neural response in obsessive-compulsive disorder patients with washing compared with checking symptoms to disgust. Psychological Medicine 30, 1037-1050.

Phillips, M.L., Medford, N., Young, A.W., Williams, L., Williams, S.C.R., Bullmore, E.T., Gray, G.A., Brammer, M.J., 2001. Time courses of left and right amygdalar responses to fearful facial expressions. Human Brain Mapping 12, 193-202.

Poline, J.B., Mazoyer, B.M., 1994. Enhanced detection in brain activation maps using a multifiltering approach. Journal of Cerebral Blood Flow and Metabolism 14, 639-642.

Rasmussen, S.A., Eisen, J.L., 1992. The epidemiology and differential diagnosis of obsessive compulsive disorder. Journal of Clinical Psychiatry 53 (Suppl.), 4-10. 
Rauch, S.L., Jenike, M.A., Alpert, N.M., Baer, L., Breiter, H.C., Savage, C.R., Fischman, A.J., 1994. Regional cerebral blood flow measured during symptom provocation in obsessivecompulsive disorder using oxygen 15-labeled carbon dioxide and positron emission tomography. Archives of General Psychiatry 51, 62-70.

Rauch, S.L., Shin, L.M., Dougherthy, D.D., Alpert, N.M., Fischman, A.J., Jenike, M.A., 2002. Predictors of fluvoxamine response in contamination-related obsessive compulsive disorder: a PET symptom provocation study. Neuropsychopharmacology 27, 782-791.

Rosenberg, D.R., Keshavan, M.S., O’Hearn, K.M., Dick, E.L., Bagwell, W.W., Seymour, A.B., Montrose, D.M., Pierri, J.N., Birmaher, B., 1997. Frontostriatal measurement in treatment-naive children with obsessive- compulsive disorder (see comments). Archives of General Psychiatry 54, $824-830$.

Sanavio, E., 1988. Obsessions and compulsions: the Padua Inventory. Behaviour Research and Therapy 26, 169-177.

Saxena, S., Brody, A.L., Ho, M.L., Alborzian, S., Maidment, K.M., Zohrabi, N., Ho, M.K., Huang, S.C., Wu, H., Baxter Jr., L.R., 2002. Differential cerebral metabolic changes with paroxetine treatment of obsessive-compulsive disorder versus major depression. Archives of General Psychiatry 59, 250-261.

Scarone, S., Colombo, C., Livian, S., Abbruzzese, M., Ronchi, P., Locatelli, M., Scotti, G., Smeraldi, E., 1992. Increased right caudate nucleus size in obsessive-compulsive disorder: detection with magnetic resonance imaging. Psychiatry Research: Neuroimaging 45, 115-121.

Schaefer, S.M., Jackson, D.C., Davidson, R.J., Aguirre, G.K., Kimberg, D.Y., Thompson-Schill, S.L., 2002. Modulation of amygdalar activity by the conscious regulation of negative emotion. Journal of Cognitive Neuroscience 14, 913-921.

Schienle, A., Stark, R., Walter, B., Blecker, C., Ott, U., Kirsch, P., Sammer, G., Vaitl, D., 2002. The insula is not specifically involved in disgust processing: an fMRI study. NeuroReport 13, 2023-2026.

Schwartz, J.M., Stoessel, P.W., Baxter Jr., L.R., Martin, K.M., Phelps, M.E., 1996. Systematic changes in cerebral glucose metabolic rate after successful behavior modification treatment of obsessive-compulsive disorder. Archives of General Psychiatry $53,109-113$.

Shepp, L.A., Vardi, Y., 1982. Maximum likelihood reconstruction for emission tomography. IEEE Transactions on Medical Imaging 1, 113-122.

Siegle, G.J., Steinhauer, S.R., Thase, M.E., Stenger, A., Cameron, C.S., 2002. Can't shake that feeling: event-related fMRI assessment of sustained amygdala activity in response to emotional information in depressed individuals. Biological Psychiatry 51, 693-707.

Sprengelmeyer, R., Young, A.W., Calder, A.J., Karnat, A., Lange, H.W., Homberg, V., Perrett, D.I., Rowland, D., 1996. Loss of disgust: perception of faces and emotions in Huntington's disease. Brain 119, 1647-1665.

Sprengelmeyer, R., Young, A.W., Pundt, I., Sprengelmeyer, A., Calder, A.J., Berrios, G., Winkel, R., Vollmoeller, W., Kuhn, W., Sartory, G., Przuntek, H., 1997. Disgust implicated in obsessivecompulsive disorder. Proceeding of the Royal Society London: Biological Sciences 264, 1767-1773.

Sprengelmeyer, R., Rausch, M., Eysel, U.T., Przuntek, H., 1998. Neural structures associated with recognition of facial expressions of basic emotions. Proceeding of the Royal Society London: Biological Sciences 265, 1927-1931.

Swedo, S.E., Schapiro, M.B., Grady, C.L., Cheslow, D.L., Leonard, H.L., Kumar, A., Friedland, R., Rapoport, S.I., Rapoport, J.L., 1989. Cerebral glucose metabolism in childhood-onset obsessive-compulsive disorder. Archives of General Psychiatry 46, $518-523$.

Swedo, S.E., Pietrini, P., Leonard, H.L., Schapiro, M.B., Rettew, D.C., Goldberger, E.L., Rapoport, S.I., Rapoport, J.L., Grady, C.L., 1992. Cerebral glucose metabolism in childhood-onset obsessive-compulsive disorder. Revisualization during pharmacotherapy. Archives of General Psychiatry 49, 690-694.

Szeszko, P.R., Robinson, D., Alvir, J.M., Bilder, R.M., Lencz, T., Ashtari, M., Wu, H., Bogerts, B., 1999. Orbital frontal and amygdala volume reductions in obsessive-compulsive disorder. Archives of General Psychiatry 56, 913-919.

Talairach, J., Tournoux, P., 1988. Co-planar Stereotaxic Atlas of the Human Brain. Thieme Medical Publishers, New York.

van den Heuvel, O.A., Boellaard, R., Veltman, D.J., Mesina, C., Lammertsma, A.A., 2003. Attenuation correction of PET activation studies in the presence of task-related motion. NeuroImage 19, 1501-1509.

van Oppen, P., Hoekstra, R.J., Emmelkamp, P.M.G., 1995. The structure of obsessive-compulsive symptoms. Behaviour Research and Therapy 33, 15-23.

Whalen, P.J., Shin, L.M., McInerney, S.C., Fischer, H., Wright, C.I., Rauch, S.L., 2001. A functional MRI study of human responses to facial expressions of fear versus anger. Emotion 1, 70-83.

Wright, C.I., Fischer, H., Whalen, P.J., McInerney, S.C., Shin, L.M., Rauch, S.L., 2001. Differential prefrontal cortex and amygdala habituation to repeatedly presented emotional stimuli. NeuroReport 12, 379-383. 